\title{
GDC learning outcomes for the undergraduate dental curriculum
}

\author{
Nicola Innes \\ University of Dundee, Unit of Dental and Oral Health, Park Place, Dundee \\ Dominic Hurst \\ Queen Mary University of London, Barts \& The London School of Medicine and Dentistry, Institute of Dentistry, UK
}

The GDC's publication 'Preparing for practice - Dental team learning outcomes for registration' has put evidence-based practice at its core. ${ }^{1}$ It states, as outcome 1.1.1:

for dentists, 'Explain, evaluate and apply the principles of an evidence-based approach to learning, clinical and professional practice and decision making' and

for dental therapists, hygienists, nurses, orthodontic therapists, clinical dental technicians, and dental technicians, 'Describe the principles of an evidencebased approach to learning, clinical and professional practice and decision making'

Here, we consider some of the implications of these outcomes as dental schools throughout the UK continue to embed them in their curricula. Are we clear what the principles of EBD are? How are we going to ensure that we really deliver these and how will we do this most effectively? Do we simply support undergraduates in learning how to use EBD principles, or should we be going further and encouraging them to become generators of evidence too?

\section{Principles, what principles?}

Evidence-based practice has, since the 1990s, emphasised that clinicians use high quality, up-to-date research in combination with their clinical expertise and their patients' values to inform their clinical decisions. $^{2}$

The classic five step process of 'doing' EBD consists of structuring a clinical question so that it is answerable, finding the highest quality research, critically appraising it, making a decision on its application (if? and how?) and evaluating it. ${ }^{3}$ It would be easy to see this framework as all there is to EBD, however, that would leave it lacking in context and without depth of meaning. Because, whilst the framework helps identify the research component (best evidence) of the evidence-based practice triad, it doesn't directly address the meaningful integration of the evidence with the other two (clinical expertise and patient values). Do we need to think more about how we encourage and support students in weighing this research within the context of their present and future clinical experience? And will we put as much emphasis on teaching students how to elicit and understand the values of their patients, as we do on finding the most appropriate trials or systematic reviews?

In the five step process, the first three question, search, appraise - may seem to be the easiest to teach and deliver in traditional courses. Much of this teaching may take place away from the clinics and patients, with scenarios that send students off to generate clinical questions, find research papers and to critically appraise them. The EBD process (and our professional obligations!) requires, though, that this research be applied. We must strive to ensure that all the principles - whilst known and understood by students - don't get left in a sterile learning environment that is distant from the clinic. Finding ways to facilitate faculty - both part- and full-time - to enable students to apply their learning in the clinic with patients, will be key to delivering this essential element of EBD. This will help to ensure the second and third elements of the EBD triad are as strong as the best evidence one.

The five stage EBD process includes evaluation, which has several facets. First, in the same way that clinical governance requires us to conduct audit to assess our clinical effectiveness, evaluating the effect of introducing a particular evidence-based approach to our patients' management can encourage its continued implementation, its modification or a return to the old way of doing things. Second, we may want to appraise our own performance in going through the previous steps of the EBD process and how we might improve on this.

But evaluation of EBD has a third and very important aspect. The clinician who decides on an evidence-based change of practice will want to understand why their patients react the way they do, why other members of the team are or aren't buying into it, and also, how much it is costing to deliver. So, evaluation is complex, but it is as important as the other stages in the EBD process if there is to be a real and meaningful change in practice.

\section{Teaching the principles}

How will we teach these EBD principles? Stand-alone courses are unlikely to be as effective as incorporating EBD into clinical teaching. ${ }^{3}$ Clinical teaching needs to be underpinned by the principles of EBD from the outset in order for students to value it in the way we would like. Furthermore, since a significant mode of learning is through modelling, ${ }^{4}$ it is incumbent on clinical teachers to be using EBD and clearly demonstrating that use in the clinic during their care of patients, if students are to value it and learn to use it too.

Teaching EBD is one thing, assessing it is another. The recently published Sicily statement on classification and development of evidence-based practice learning assessment tools ${ }^{5}$ covers some of the challenges for evaluating teaching and learning and there are tools developed and validated already for use specifically in the dental undergraduate curriculum. ${ }^{6}$ As this element of teaching matures within our curricula, we would do well to assess how it is changing our students' attitudes towards, and understanding of, the EBD process so that we can work out how to further enhance it.

\section{Evidence generators as well as evidence users}

Whilst the five stage EBD process is an essential beginning, are we content that our graduates simply be users of evidence? We will all be aware of the number of systematic reviews that cry out in hope for more high quality research to be conducted. ${ }^{7-9}$ Are we preparing clinicians to be partners 
in generating such research? Again, looking to 'Preparing for practice', Section 9.5 states that dentists 'Recognise and evaluate the impact of new techniques and technologies in clinical practice' and Section 10.8 'Demonstrate appropriate continuous improvement activities'. However, these fall short of calling on us to equip our graduates with the mindset and skills to participate in research. This is a missed opportunity.

A 2009 Higher Education Academy document ${ }^{10}$ called on all undergraduate curricula to involve research. For the profession to use EBD effectively for the benefit of patients it needs to be generating the high quality clinical evidence from which it can draw. But if, when designing our curricula, we adhere to the GDC learning outcomes alone we will not be training our graduates to contribute either as research leaders or partners in research. We must go further and train men and women of science ${ }^{11}$ who can embrace complex problems and engage with them critically and so improve the care we are able to provide for our patients.

1. General Dental Council. Preparing for practice: Dental team learning outcomes for registration. London, 2012, p. 16.

2. Sackett DL, Rosenberg WM, Gray JA, Haynes RB, Richardson WS. Evidence based medicine: what it is and what it isn't. BMJ 1996; 312: 71-72. Epub 1996/01/13.

3. Straus SE. Evidence-based medicine : how to practice and teach it. 4th ed. Edinburgh: Elsevier Churchill Livingstone, 2011.

4. Kenny NP, Mann KV, MacLeod H. Role modeling in physicians' professional formation: reconsidering an essential but untapped educational strategy. Acad Med 2003; 78: 1203-1210. Epub 2003/12/09.

5. Tilson JK, Kaplan SL, Harris JL, et al. Sicily statement on classification and development of evidence-based practice learning assessment tools. BMC Med Educ 2011; 11: 78. Epub 2011/10/06.
6. Hendricson WD, Rugh JD, Hatch JP, Stark DL, Deahl T, Wallmann ER. Validation of an instrument to assess evidence-based practice knowledge, attitudes, access, and confidence in the dental environment. / Dent Educ 2011; 75: 131-144. Epub 2011/02/05.

7. Nadin G, Goel BR, Yeung CA, Glenny AM. Pulp treatment for extensive decay in primary teeth. Cochrane Database Syst Rev 2003(1): CD003220. Epub 2003/01/22

8. Del Fabbro M, Taschieri S, Testori T, Francetti L, Weinstein RL. Surgical versus non-surgical endodontic re-treatment for periradicular lesions. Cochrane Database Syst Rev 2007(3): CD005511. Epub 2007/07/20.

9. Weston P, Yaziz YA, Moles DR, Needleman I. Occlusal interventions for periodontitis in adults. Cochrane Database Syst Rev 2008(3): CD004968. Epub 2008/07/23.

10. Healey $M$, Jenkins $A$. Developing undergraduate research and inquiry. The Higher Education Academy; 2009 [cited 2012 11/02/2012]; Available from: http:// www.heacademy.ac.uk/assets/documents/resources/ publications/DevelopingUndergraduate_Final.pdf.

11. Bertolami CN. The role and importance of research and scholarship in dental education and practice. J Dent Educ 2002; 66: 918-924; discussion 925-926. Epub 2002/09/07.

Evidence-Based Dentistry (2012) 13, 2-3. doi:10.1038/sj.ebd.6400384 . 